\title{
Review
}

\section{Argumentation Theory: A Pragma-Dialectical Perspective}

\author{
By Frans H. van Eemeren
}

Cham: Springer International Publishing, 2018. ISBN 978-3-31995381-6.

\section{Reviewed by DAVID ZAREFSKY}

Department of Communication Studies

Northwestern University

Evanston, IL

USA

d-zarefsky@northwestern.edu

\begin{abstract}
This article reviews Frans H. Résumé: Cet article est une critique de van Eemeren's Argumentation Theory: Théorie de l'argumentation: une A Pragma-Dialectical Perspective perspective pragma-dialectique (Springer 2018). (Springer 2018) de Frans H. van Eemeren.
\end{abstract}

Keywords: Argument structures, argumentation theory, communicative activity types, critical discussion, pragma-dialectics, rhetorical argumentation, strategic maneuvering, theory-building

The most robust approach to argumentation theory today, without question, is pragma-dialectics, formulated over a period of forty years by Frans van Eemeren and his collea gues at the University of Amsterdam. This is true whether one's criterion is the scope of topics it has been employed to address, or the number of its adherents (especially outside North America), or the pace with which its chief proponents publish research results and theoretical elaborations. This 
last criterion poses a special challenge both for students seeking a way into this theoretical perspective and for scholars wishing to stay abreast of the pragma-dialecticians' work. There is so much out there; how does one know where to begin? One cannot simply pick up the book or article of one's choice and start anywhere. Some works presuppose others, if not formally then in the sense of an evolving research trajectory. Some works are avowedly theoretical, some are grounded in the reality of actual argumentative practice, and some blend the two. Some are clearly normative and prescriptive, setting forth rules for the proper conduct of a critical discussion. Others, in contrast, are primarily descriptive, naming or characterizing strategic moves by which arguers respond to the constraints inherent in a particular activity type. But if dipping into the tradition at random will skew one's understanding, the seemingly sensible alternative of reading pragma-dialectics chronologically suffers from a practical problem: one never will catch up, so steady is the outpouring of new research and theory. What one needs, it seems, is a guide, a sort of companion to the pragma-dialectical project. It would seek to answer basic questions such as: What exactly is this perspective on argumentation theory? What are its underlying assumptions? What sorts of conclusions does it yield? How would one employ it? What are its vocabulary, tools, and apparatus? What are its limitations?

While not answering every one of these questions precisely, this is the general task Frans van Eemeren assumes in his new book, Argumentation Theory: A Pragma-Dialectical Perspective. This book does not present new directions or advanced research; that is not its aim. Rather, it is a work of synthesis. It draws together the central tenets of this approach to argumentation theory. It is akin to the author's 2004 work, A Systematic Theory of Argumentation (Cambridge University Press), but it subsumes the earlier volume, bringing it up to date while accounting for advances over the past fifteen years, and the explanations in the new work are more accessible for beginners. It can be read profitably as one of the texts in an undergraduate course in argumentation, but it can be used equally well as a reference source for scholars not trained in pragma-dialectics but wishing to unravel its seeming esoterica.

The book achieves the goal set out in the Preface: to provide "a general introduction into argumentation theory" but to "explain the 
theorizing in a pragma-dialectical way" (vii). This combines the pragmatic assumption that argumentation is goal-directed behavior with the dialectical assumption that it is part of a critical exchange aimed at resolving a difference of opinion. That it is an exchange between interlocutors, that those interlocutors proceed critically with the goal of resolution, and that what they try to resolve are differences of opinion, are among the theory's underlying assumptions that for the most part are treated only implicitly. But it bears noting, as van Eemeren sometimes has said in response to critics, that behavior falling outside these definitional boundaries, even though it might be called argumentation by others, is simply not the concern of pragmadialectics.

Chapter 1 offers a general overview of argumentation theory as a discipline and introduces key concepts and terms. A real or imagined difference of opinion calls argumentation into being. In response, arguers create a constellation of propositions that can be structured into standpoints and argument schemes that support or challenge them. Argumentation theory is the academic discipline that examines this phenomenon in order to provide "instruments for analyzing, evaluating, and producing argumentative discourse in an adequate way" (p. 5), and, by implication, to improve its quality. The discipline has both normative and descriptive components. The chapter also introduces the differences among multiple, coordinative, and subordinative structures of argument and the importance of studying fallacies. It concludes with the observation that the current state of the art emphasizes the blending of dialectical and rhetorical approaches to argumentation. Although van Eemeren reserves treatment of it for a later chapter, strategic maneuvering is the pragma-dialectician's pathway to this blending.

Chapter 2 is concerned with the process of theory-building. Four meta-theoretical principles are offered: functionalization (the theory should contribute to the goal of resolving a difference of opinion on the merits), socialization (it is based on interaction between the parties), externalization (its standpoints and moves are available for public scrutiny; they are not internal psychological states), and dialectification (it is viewed from the theoretical ideal of a critical discussion). Each of these principles is explained, often by reference to speech-act theory. From his background in sociolinguistics, van 
Eemeren was led naturally to speech-act theory in his initial framework, and his early work sets out to describe the speech-act types that are appropriate for the various stages of a critical discussion. In a chronological account of the theory's development, this chapter is foundational. But in a conceptual account, it is not evident that speechact theory warrants this pride of place. It seems that one could approach the basic tenets of pragma-dialectics without reference to it.

What is clearly foundational, however, is Chapter 3, which is devoted to the model of a critical discussion. This is a discussion devoted entirely to resolving a difference of opinion on the merits. It is "a theoretically motivated idealization" (p. 35), not an empirical reality. It is thus akin to Perelman and Olbrechts-Tyteca's "universal audience" or to Habermas's "ideal speech situation": a counterfactual norm from which one can derive rules for behavior. The chapter describes argumentative moves in such a discussion as speech-acts, and the same question noted above applies here. Two other topics are introduced in this chapter that do not seem uniquely related to the model of critical discussion: the dialectical profile, a heuristically valuable map of the possible moves an arguer might make in a particular situation (pp. 42-44), and the three argument schemessymptom, cause, and analogy - that van Eemeren has acknowledged in his research program. Interestingly, the term "argument scheme" is here left undefined except to refer to it as a "type of argument."

Chapter 4 takes up the identification of fallacies. This is one of the most important contributions to the pragma-dialectical project. Traditionally, fallacies have been understood as errors of form, such that the conclusion does not follow from the premises. Informal logic makes form subject to context, requiring subjective judgments about whether an argument is fallacious in a given case. For pragmadialectics, however, a fallacy is a particular kind of procedural error (p. 62). Specifically, it is a move in a dialogue that does not contribute to the goal of resolving a difference of opinion on the merits. It is thus not serving its proper function. In the more extended pragmadialectical theory, fallacies are described as derailments of strategic maneuvering. The railroad-safety metaphor suggests that a fallacy is a move that takes the discussion off track instead of blending rhetorical and dialectical standards of adequacy. This is a novel and promising treatment of fallacies as argumentative, not strictly logical, errors. 
The fifth chapter provides tools for descriptive studies of argumentation. They include argumentative indicators (words such as "because," "although," and "since" that show the influence of one statement on another) and indicators of "hidden fallaciousness" that often go undetected because they mirror legitimate inferences. Chapter 6 continues the analytic emphasis by focusing on the reconstruction of ordinary-language arguments into pragma-dialectical form by means of addition, deletion, substitution, and permutation (rearrangement) of the contents, and by means of the analytic overview, which is a summary of the results of the reconstruction. The chapter concludes with a discussion of the textual, contextual, and background resources available for constructing the analytic overview.

Chapter 7 takes up the important subject of strategic maneuvering, which is probably the greatest alteration of the original pragmadialectic theory. It is the bridge between the original scope of the theory and its extended version. In the original theory, rhetorical considerations of effectiveness were largely neglected, as if they would not be present in a critical discussion. But recognizing what he calls the "argumentative predicament" (p. 111), the need to account for both reasonableness and effectiveness, van Eemeren posits topical potential, audience demand, and presentational choices as categories within which arguers legitimately make rhetorical adjustments while fulfilling their dialectical obligations. Strategic maneuvering relates to pragma-dialectics because it acknowledges attenuations of the norms of critical discussion to recognize the conventions of argumentative reality in given cases. Abstracting from specific maneuvers, argumentative strategies can be understood as designs for conducting strategic maneuvering (p. 116). Van Eemeren insists that the study of strategic maneuvering makes it clear that dialectical and rhetorical perspectives are complementary, not incompatible.

What follows next is a discussion of different communicative activity types, of which speech events appear to be tokens. Strategic maneuvering does not devolve all the way from abstract norms to particular cases. Communicative activity types are categories of discourse that share conventionalized norms. Negotiation, storytelling, prayer, and debating are examples of communicative activity types. They arise in particular domains of human action. This is illustrated with reference to the political, legal, and medical domains-three 
which pragma-dialecticians have especially focused on. Chapter 9 continues this inquiry by asking what are the distinctive features of argumentation that arise in different domains as a result of complying with their institutional preconditions, acknowledging constraints and exploiting opportunities. This is the most recent theoretical foray in van Eemeren's research. He proposes that pragmatic (means-end) argumentation is prototypical for the political domain, consultation and promotion for the medical domain, and rules-based reasoning for the legal domain (pp. 151-153). He predicts that this line of research will yield more precise insights about context-dependency and independency of arguments.

The utility of the search for prototypical argumentative patterns is illustrated with a detailed case study of the European Parliament, especially the assumption that a member must both represent the views of his or her national constituency and also speak for the interests of the European Union as a whole. The assumption that Members of the European Parliament have a dual constituency affects what can be said in certain situations, how challenges to one's arguments can be responded to, and the importance of balance as a topos of self-defense. This line of arguing should be productive; its early yield includes analytical insight and empirical validation. But it is hard to see how it is uniquely (or even especially) a project of pragma-dialectics. The domains that van Eemeren investigates seem to be the same entities as argument fields in Toulmin's system or spheres of argument according to Goodnight's. And the goal of locating prototypical argumentative patterns seems to be the same, regardless of the approach.

The final chapter examines pragma-dialectics in comparison to other approaches to argumentation theory. Van Eemeren discusses the approaches of Stephen Toulmin and of Chaim Perelman and Lucie Olbrechts-Tyteca, which are known more by their authors' names than by any formal titles bestowed upon them. He then compares pragmadialectics successively to formal dialectical models, informal logic, and rhetorical and linguistic approaches. Most of these comparisons are elaborated in the coedited Handbook of Argumentation Theory. The key features of each alternative are presented fairly, and the comparisons are mostly non-judgmental. Yet the presentation of each approach is necessarily filtered through the lens of pragma-dialectics, which largely escapes criticism in these accounts. One reason for the 
popularity of pragma-dialectics, I suspect, is that it can envelop alternative approaches. When a rhetorician maintains, for example, that argumentation addressed to a mass audience is fundamentally different from interpersonal deliberation, the pragma-dialectician can reply that the mass audience can be understood as just so many simultaneous dialogue partners. Yes, it can be understood that way, but the question is whether that is the best way to present it. And when an informal logician claims that that approach is different yet, van Eemeren maintains that there is so much common interest that informal logicians and pragma-dialecticians should "join forces" (p. 179). This is not intellectual imperialism; it is the natural result of seeing one's interlocutors through one's own eyes.

I wonder if it might have made a stronger ending to use these alternative approaches to unpack the underlying assumptions of pragma-dialectics itself. For example, what do we gain or lose by seeing the interpersonal critical discussion as the normative model of argumentation? What are the consequences of privileging resolution of differences of opinion as the goal of argumentation? Is it more desirable to derive procedures and rules of argumentation from a normative-theoretic model or to build them from actual cases of argumentation? What assumptions underlie making reasonableness one's goal? And so on. These are questions whose answers are largely taken for granted. In fairness, this is not a situation unique to pragmadialectics. No approach to argumentation theory is particularly strong at identifying and examining its own underlying assumptions.

Many readers of this journal already will be familiar with pragmadialectics. For them, this book will be valuable as a coherent distillation and systematic presentation of the theory's major tenets at this point in its evolution. Others will have encountered an overview of pragma-dialectics through the words of an adherent of some other approach. This book offers an authentic reading of the theory as explained by its own authors and adherents. And for those not yet familiar with pragma-dialectics, this compact but comprehensive volume provides an accessible account of an influential line of theorybuilding and research.

One final note: While Chapter 10 implies the existence of multiple approaches to argumentation theory, each of which should be validated by allowing it to speak in its own voice, Chapter 9 points to the 
possibility of convergence: the possibility that theorists of different orientations, working from different starting points and underlying assumptions, using different vocabularies may actually be addressing many of the same problems. To the degree that they do, that circumstance raises the possibility that our different orientations may yet yield a unified theory of argumentation. If so, I would not be surprised to find that pragma-dialectics has a head start on imagining what it looks like. That is yet another reason that van Eemeren's new book belongs in the libraries of scholars throughout the argumentation community. 